\title{
Usage of herbal medicines among the elderly in a primary care unit in Hat Yai, Songkhla province, Thailand
}

\author{
Thareerat Ananchaisarp ${ }^{1, * \odot}{ }^{\circ}$, Supeecha Rungruang ${ }^{1 \oplus}$, Saralee Theerakulpisut ${ }^{2 \odot}$, \\ Peerada Kamsakul ${ }^{2 \oplus}$, Nichapat Nilbupha ${ }^{2 \odot}$, Napat Chansawangphop ${ }^{2 \odot}$, Jirameth Yiambunya ${ }^{2 \oplus}$, \\ Jirayu Jarudamrongsak ${ }^{2 \odot}$, Kanokwan Prasertsri ${ }^{2 \odot}$
}

\begin{abstract}
Background: The prevalence of chronic diseases in the elderly is high, and some use herbal medicines instead of, or together with, conventional medicine. Herbal medicine usage may cause adverse events.

Objectives: To determine the prevalence of herbal medicine usage among the elderly attending a primary care unit (PCU) of Songklanagarind Hospital, a tertiary teaching hospital in Hat Yai, Songkhla province, Thailand, and associated factors, reasons for use, principles considered before use, perceived effects, and history of consultation with medical professionals concerning their herbal medicine usage.

Methods: We conducted a cross-sectional survey of a convenience sample of elderly patients who visited the PCU. Questionnaires were used to obtain data.

Results: We included 204 patients who met the eligibility criteria. About two-thirds were women, with a median age of 69.0 years. Most had underlying diseases and were educated. The all time prevalence of herbal medicine usage was $60.8 \%$. Being educated was significantly associated with herbal medicine usage. Among 124 users, $79 \%$ did not consider any principles for safe use of herbal medicine, $63 \%$ had no knowledge of possible interactions with conventional medicines, and $73 \%$ had never been asked about their use of herbal medicines by their health care professionals.

Conclusions: There is a high prevalence of herbal medicine usage among the elderly Thai patients attending the PCU, especially by the educated. The majority did not consider the principles for safe use of herbal medicine. Health care providers should be more aware of herbal medicine usage and should increase their role in initiating a discussion about herbal medicine usage with elderly patients.
\end{abstract}

Keywords: adverse reactions; elderly; herbal medicine; herb-drug interactions; primary health care

Most populations now have a longer life expectancy than before, and so the prevalence of chronic diseases is increasing [1]. Because chronic diseases are incurable, with some diseases requiring complex regimen or incurring high medical expenses, some patients use herbal medicines [2], which are defined as "herbs, herbal materials, herbal preparations and

*Correspondence to: Thareerat Ananchaisarp, Family Medicine Unit, Department of Family and Preventive Medicine, Songklanagarind Hospital, Faculty of Medicine, Prince of Songkla University, Karnjanavanich Road, Hat Yai, Songkhla 90110, Thailand, e-mail: thareerat.a@psu.ac.th

'Department of Family and Preventive Medicine, Faculty of Medicine, Prince of Songkla University, Hat Yai, Songkhla 90110, Thailand

${ }^{2}$ Graduate School of Medicine, Faculty of Medicine, Prince of Songkla University, Hat Yai, Songkhla 90110, Thailand

Ә Open Access. @ 2021 Ananchaisarp et al., published by Sciendo. (c) BY-NC-ND This work is licensed under the Creative Commons Attribution NonCommercial-NoDerivatives 4.0 License. 
finished herbal products that contain parts of plants as active ingredients, or other plant materials, or combinations" [3]. Previous studies have shown various prevalence of herbal medicine usage in the elderly, ranging $12.0 \%-97.4 \%$ [4-10] and depending on the study population and setting. The usage of herbal medicines is common within the Thai population, due to a positive attitude and knowledge about herbal medicines relayed from generation to generation. Thai traditional herbal medicines are legal and accepted, with some herbal medicines being included in the Thai national drug lists. Moreover, these herbal medicines are easy to access, via multiple sources, without a doctor's prescription, such as through a pharmacy or websites. A study indicated that $97.4 \%$ of elderly Thai people reported an experience of herbal medicine usage [10]. Being an elderly woman, having higher education, having a good income, and an increasing number of underlying diseases is associated with higher prevalence of herbal medicine usage. By contrast, very advanced age was associated with a lower prevalence of herbal medicine usage [4-6, 8].

Common conditions associated with herbal medicine usage are stroke, cancer, and arthritis [4]. The perceptions of herbal medicine use are reduced medical expenses, that they cure diseases, relieve symptoms, and provide good health [10]. However, herbal medicines can be sold and marketed without safety and efficacy profiles, which are required for pharmaceutical drugs. Although some herbal medicines have scientific evidence for their efficacy, such as gingko, which is possibly effective for the treatment of dementia, other herbal medicines are associated with adverse events. Adverse drug events, such as nephrotoxicity, hepatotoxicity, or carcinogenicity, can be caused by the active ingredients of the constituent herbs $[2,7,11]$ and contaminants in herbal medicines, such as heavy metals [12], or by interactions between herbal and conventional medicines [5-7, 13, 14]. These adverse events may have a higher chance of occurrence in the elderly because of their lower body capacity, high levels of comorbidities, and the number of medications taken. Most users are not aware of the problem of drug interactions [15].

For use of safe herbal medicine, elderly people should consider several factors before deciding to use a herbal medicine, such as, but not limited to, the 4 principles to consider before using complementary and alternative medicine, indicated by the Faculty of Medicine Ramathibodi Hospital, Mahidol University, namely, product reliability, safety, efficacy, and cost-benefit effectiveness [16]. Less than half of elderly users of herbal medicine consulted health care providers regarding herbal medicine use $[5,8,13]$, and only $16.6 \%$ of users were asked about their herbal medicine usage by their physicians [9].
Although many studies have reported the prevalence and factors related to herbal medicine usage, only a few have been conducted in Thailand and even those in limited settings. These studies have evaluated patient concerns and physician's attention to herbal medicine usage in the elderly. Therefore, the present study had the primary objective of determining the prevalence of herbal medicine usage in the elderly attending a primary care unit (PCU) of a tertiary teaching hospital in Hat Yai, Songkhla province, Thailand; with secondary objectives being to determine factors associated with use, reasons for use, principles considered before use, perceived effects, and history of consultation with medical professionals concerning herbal medicine use.

\section{Methods}

\section{Study design and setting}

The present study was approved by the Ethics Committee of the Faculty of Medicine, Prince of Songkla University, Hat Yai, Songkhla province, Thailand (REC. No. 62-222-9-1). The present study was conducted in compliance with the contemporary revision of the Declaration of Helsinki and the International Conference on Harmonization in Good Clinical Practice. All participants signed informed consent forms after reading the participant information sheet and having it explained to them. This cross-sectional study was conducted in the PCU of Songklanagarind Hospital, from September 2 to 20, 2019. The PCU provides primary health care services for adult and elderly patients within Songklanagarind Hospital, a tertiary care, university teaching hospital of Prince of Songkla University in southern Thailand.

\section{Study sample and sampling}

We included elderly patients (aged $\geq 60$ years), who attended the PCU of Songklanagarind Hospital during the study period, with any complaint, who were able to communicate in Thai, and who consented to participate in our research. We excluded patients who required emergency treatment such as a hypertensive crisis. Sample size was calculated based on the primary objective of this study, by using a population proportion formula, $n=Z^{2}{ }_{1-\alpha / 2} p(1-p) / d^{2}$; we used the prevalence of current usage of herbal medicines in the elderly who visited the geriatric clinic, at a tertiary care hospital in Bangkok, Thailand, for the power calculation, being 15.0\% [13], 95\% confidence interval (CI), a precision error of 5\%; 196 participants were required and we added a further $10 \%$ to account 
for potentially missing data. We enrolled patients who were compatible with the eligibility criteria, by convenience sampling method; then we excluded questionnaires with incomplete information, providing data from a remaining total of 204 patients for analysis.

\section{Variables}

We used questionnaires to assess the primary outcome: "herbal medicine usage," in which the answers were divided into 3 groups (never used, history of usage, but stopped using for more than 1 year, and current usage, which means a history of herbal medicine use within 1 year) as well as related factors, which were derived from a review of the literature. In addition, we added information about details of herbal medicine usage such as product name, reason and person who recommended their use, health results after using, and experience of physician interviews. The data collection form was sent to 3 expert investigators to determine an Item Objective Congruence (IOC) index score for each question. The results showed an IOC $<0.5$ for 2 questions, which were corrected as recommended until IOC $\geq 0.5$ for all questions was reached before use. All researchers were trained for standardization and we conducted a pilot study in elderly patients at another PCU, which was close to our study setting.

\section{Data collection}

Four researchers searched for patients who fitted the eligibility criteria of our study; then they performed a consent process, by explaining the details of the research to the participants, and obtained written informed consent. Another 4 researchers, who were trained in questionnaire use, directly asked participants the questions, as we had considered the vision problems of some elderly patients. We then confirmed some of the data with the hospital information system.

\section{Data management and analysis}

Data were entered in EpiData (version 3.1, Denmark), with a double-entry basis, and were analyzed using $\mathrm{R}$ software ( $\mathrm{R}$ Core Team 2017). Descriptive statistical analysis was used to report the baseline characteristics of the patients, prevalence, and detail of herbal medicine use. We presented categorical data in terms of percentage, while continuous data were checked for normal distribution, and median with interquartile range (IQR) was used when normal distribution assumption was not met. We used multivariate logistic regression to test the relations between the associated factors and herbal medicine usage. Data are presented as odds ratio (OR), with $95 \%$ CIs. $P<0.05$ was considered significant.

\section{Results}

The baseline characteristics of 204 elderly patients are shown in Table 1. Two-thirds were women, married, and unemployed. Median age (IQR) was 69.0 (9.0) years, and most patients had some degree of education. Almost all patients had underlying diseases, with the median number of underlying diseases (IQR) being 2.0 (1.0); most common underlying diseases were dyslipidemia and hypertension.

Prevalence of herbal medicine usage is shown in Table 2. More than half of the patients had a history of using herbal medicines, and $49.5 \%$ were had used them within the past year. Table 3 shows the details of patients with a history of herbal medicine usage. The common reasons that elderly patients used herbal medicines was thinking that herbal medicines are interesting and they expected herbal medicines to add benefit to conventional medicine, especially for cardiovascular, gastrointestinal, and respiratory systems. About $80.0 \%$ of patients using herbal medicines did not consider any principles of safe use of herbal medicine before consumption. In groups that considered safe use of herbal medicine, "product reliability," was the most common issue of patient concern. About $20 \%$ of patients initiated use by themselves or after receiving advice from neighbors or relatives. Two-thirds of patients received benefits after use, while $4.8 \%$ experienced side effects such as diarrhea. More than half did not know that herbal medicines may interact with conventional medicine. Two-thirds of the patients would disclose their history of herbal medicine usage to health care providers only if they were asked, but only a quarter had ever been asked by health care providers.

About half of the elderly patients had used a herbal medicines within the past 1 year: the name and number of herbal medicine used are shown in Table 4. About $40 \%$ of patients used at least 2 herbal medicines together, and $2 \%$ used 7 herbal medicines simultaneously. The 3 most common herbal medicines used were kariyat, turmeric, and bai yanang. Factors associated with herbal medicine use are shown in Table 5. Being educated was a significantly associated factor with increased prevalence of herbal medicine usage $(P=0.03)$.

\section{Discussion}

More than half of the elderly patients who attended the PCU had been using herbal medicines, especially educated patients. 
Table 1. Patient characteristics $(n=204)$

\begin{tabular}{|c|c|}
\hline Characteristic & Number (\%)† \\
\hline \multicolumn{2}{|l|}{ Sex } \\
\hline Male & $62(30.4)$ \\
\hline Female & $142(69.6)$ \\
\hline Age (years) (median [IQR]) & $69.0(9.0)$ \\
\hline \multicolumn{2}{|l|}{ Education } \\
\hline Uneducated & $13(6.4)$ \\
\hline Educated $\neq$ & $191(93.6)$ \\
\hline \multicolumn{2}{|l|}{ Marital status } \\
\hline Couple & $138(67.6)$ \\
\hline Single & $13(6.4)$ \\
\hline Widowed/divorced & $53(26.0)$ \\
\hline \multicolumn{2}{|l|}{ Career } \\
\hline No & $142(69.6)$ \\
\hline Yes & $62(30.4)$ \\
\hline \multicolumn{2}{|l|}{ Salary§ } \\
\hline No & $52(25.5)$ \\
\hline Yes & $152(74.5)$ \\
\hline \multicolumn{2}{|l|}{ Underlying diseases } \\
\hline No & $9(4.4)$ \\
\hline Yes & $195(95.6)$ \\
\hline \multicolumn{2}{|l|}{ Type of underlying diseases } \\
\hline Dyslipidemia & $145(71.1)$ \\
\hline Hypertension & $144(70.6)$ \\
\hline Diabetes mellitus & $64(31.4)$ \\
\hline Osteoarthritis & $17(8.3)$ \\
\hline Cardiovascular diseases & $14(6.9)$ \\
\hline Gout & $10(4.9)$ \\
\hline Dyspepsia & $9(4.4)$ \\
\hline Asthma/chronic obstructive pulmonary disease & $9(4.4)$ \\
\hline Cancer & $7(3.4)$ \\
\hline Allergic rhinitis & $7(3.4)$ \\
\hline Number of underlying diseases (median [IQR]) & $2.0(1.0)$ \\
\hline $\begin{array}{l}\text { Number of current medications } \| \text { per day (median } \\
{[\mathrm{IQR}] \text { ) }}\end{array}$ & $3.0(1.0)$ \\
\hline
\end{tabular}

$\mathrm{IQR}$, interquartile range.

tData are presented as $n(\%)$ unless indicated otherwise. IQR, interquartile range.

\#Educated group means patient who had some degree of education. $\S$ Salary means fixed regular income from any sources (accept elderly living allowance, a right of all elderly Thai), such as salary from work or monthly money from relatives.

\|Current medications refers to medications that patients use regularly for treatment of their underlying diseases (not including vitamin supplements or medication to treat acute illness).

The majority did not consider any principles for safe use of herbal medicine before consumption; more than half did not know that herbal medicines could interact with conventional
Table 2. Prevalence of herbal medicine usage $(n=204)$

\begin{tabular}{lc}
\hline Usage of herbal medicine & Number (\%) \\
\hline No & $80(39.2)$ \\
History of use, but stopped after more than 1 year & $23(11.3)$ \\
Current usaget & $101(49.5)$ \\
\hline
\end{tabular}

tCurrent usage means having a history of herbal medicine use within the past 1 year.

Table 3. Reasons for usage, source of influence to initiate use, disclosure to health care providers, and perceived effects after use in patients with a history of herbal medicine usage $(n=124)$

\begin{tabular}{|c|c|}
\hline Topic & Number (\%) \\
\hline \multicolumn{2}{|l|}{ Reasons for uset } \\
\hline Thought that herbal medicines are interesting & $81(65.3)$ \\
\hline $\begin{array}{l}\text { Herbal medicines may add benefits to conventional } \\
\text { medicine }\end{array}$ & $60(48.4)$ \\
\hline Health care provider suggested use & $7(5.6)$ \\
\hline Conventional medicine was ineffective & $6(4.8)$ \\
\hline Other & $8(6.5)$ \\
\hline \multicolumn{2}{|l|}{ Expected benefits $\dagger$} \\
\hline Cardiovascular system & $80(64.5)$ \\
\hline Gastrointestinal system & $36(29.0)$ \\
\hline Respiratory system & $33(26.6)$ \\
\hline Endocrine system & $28(22.6)$ \\
\hline Musculoskeletal system & $27(21.8)$ \\
\hline Other & $60(39.0)$ \\
\hline \multicolumn{2}{|l|}{ Consideration before herbal medicine usage } \\
\hline Did not consider any topic before consumption & $98(79)$ \\
\hline $\begin{array}{l}\text { Considered at least } 1 \text { of the following topics before } \\
\text { consumptiont }\end{array}$ & $26(21)$ \\
\hline Product reliability & $20(16)$ \\
\hline Safety & $8(7)$ \\
\hline Efficacy & $2(2)$ \\
\hline Cost-benefit effectiveness & $2(2)$ \\
\hline \multicolumn{2}{|l|}{ Source of influence initial usaget } \\
\hline Oneself because of their tradition or culture & $25(20)$ \\
\hline Suggestion by neighbor & $25(20)$ \\
\hline Suggestion by relatives & $24(19)$ \\
\hline Advertising media & $20(16)$ \\
\hline Suggestion by friends & $18(15)$ \\
\hline Suggestion by health care providers & $12(10)$ \\
\hline Suggestion by other patients & $9(7)$ \\
\hline Other & $13(11)$ \\
\hline \multicolumn{2}{|l|}{ Perceived effects after use } \\
\hline Beneficial & $95(77)$ \\
\hline
\end{tabular}


Table 3. Continued

\begin{tabular}{lc}
\hline Topic & Number (\%) \\
\hline No difference & $23(19)$ \\
Experienced side effects & $6(5)$ \\
Drug interaction awareness & \\
No & $78(63)$ \\
Yes & $46(37)$ \\
Preferences of disclosure to health care providers & \\
Would only report if medical professionals asked & $80(68)$ \\
Would always ask before use & $16(13)$ \\
Would always report after use & $12(10)$ \\
Would disclose only if complications occurred & $8(7)$ \\
Would not disclose about use & $4(3)$ \\
History of being asked about herbal medicine use by & \\
health care providers & \\
No & $91(73)$ \\
Yes & $33(27)$ \\
\hline
\end{tabular}

tParticipants can choose more than 1 answer.

¥Side effects included diarrhea in 3 patients, abdominal discomfort in 2 patients, and dizziness in 1 patient.

Table 4. Number and name of herbal medicine usage in current user $(n=101)$

Number

\begin{tabular}{lc}
\hline Number of herbal medicines used together & \\
1 & 63 \\
2 & 16 \\
3 & 15 \\
4 & 4 \\
5 & 1 \\
7 & 2 \\
Name of herbal medicine usedt & \\
Kariyat & 37 \\
Turmeric & 19 \\
Bai yanang & 17 \\
Laurel & 14 \\
Gotu kola & 10 \\
Ginger & 10 \\
Moringa & 9 \\
Garlic & 7 \\
Cordyceps & 7 \\
Collagen & 7 \\
Herbal medicine (name unknown) & 7 \\
Other & 17 \\
\hline Participants can choose morethan & $7 a n s w e r$ \\
\hline
\end{tabular}

†Participants can choose more than 1 answer. medicine and would only disclose a history of usage if they were asked by their health care providers.

The participants of this study were mainly women, by a factor of 2, with a median age of 69.0 years, which was comparable with previous studies $[10,17]$. About $7 \%$ of participants were not educated, although this corresponds to the results of a national survey in Thailand in 2014, which found that almost $10 \%$ of elderly Thai had never been formally educated [18]. Almost all patients had underlying diseases, especially noncommunicable diseases that are often currently incurable, resulting in some trying to find a hopeful treatment to cure their disease. In addition, this group had current, conventional medicines to control their underlying diseases. When using herbal medicine, one should be aware of adverse events from herb-drug interactions [5-7, 13, 14].

This study shows the prevalence of herbal medicine usage is being close to that by the elderly in Singapore [17], but is higher than that found by studies conducted in Western countries [4-6,9]. This may be because Asian people generally use herbal medicines more commonly than people of other ethnicities [8]. Especially within the Thai population, people have positive attitudes and easy access to herbal medicines. The common reasons for initiating herbal medicine usage are the same as those found by previous studies $[5,8,9]$. We found that herbal medicine usage is significantly higher among educated people than it was in those without formal education, with an OR of 4.12, and this result is in accordance with previous studies $[4,15]$. This may be due to educated patients being more concerned about their state of disease, having better health literacy, ease of access to information about complementary and alternative medicine, and higher perception of benefits from herbal medicine [10]. Therefore, they may be more likely to explore a larger range of therapies for the treatment of their symptoms. The 3 most common herbal medicines used by elderly Thai patients were kariyat, turmeric, and bai yanang. Kariyat (Andrographis paniculata, also known as Herba Andrographidis or fa talai jone) and turmeric are herbal medicines on the National List of Essential Medicines in Thailand, which are used by health care providers and are easy to find in pharmacies. They act via cytochrome P450, and as a result of common interactions with these enzymes can cause interactions with many drugs generally used by the elderly, such as paracetamol, omeprazole, losartan, warfarin, ibuprofen, and celecoxib. Of importance is that about twothirds of the patients were not aware of herb-drug interaction problems and would only disclose usage if they were asked by health care providers; this may have increased the incidence of herb-drug interaction problems. The bai yanang plant (Tiliacora triandra) has been widely used in Thailand with patients' expectation of benefit in cardiovascular systems, despite 
Table 5. Multivariate analysis for factors associated with herbal medicine usage in elderly patients $(n=204)$

\begin{tabular}{|c|c|c|c|c|c|}
\hline & \multicolumn{2}{|c|}{ Herbal medicine usage } & \multirow[t]{2}{*}{ Adjusted OR (95\% Cl) } & \multirow[t]{2}{*}{$P$ (Wald test) } & \multirow[t]{2}{*}{$P$ (LR test) } \\
\hline & No $(n=80)$ & Yes $(n=124)$ & & & \\
\hline Sex & & & & & 0.28 \\
\hline Male & $21(34 \%)$ & $41(66 \%)$ & 1 & & \\
\hline Female & $59(42 \%)$ & $83(59 \%)$ & 0.68 (0.34 to 1.37$)$ & 0.28 & \\
\hline Age (median [IQR]) & $68.8(8.5)$ & $69.0(9)$ & 0.99 (0.95 to 1.04$)$ & 0.90 & 0.90 \\
\hline Education & & & & & $0.03^{*}$ \\
\hline Uneducated & $9(69 \%)$ & $4(31 \%)$ & 1 & & \\
\hline Educated & $71(37 \%)$ & $120(63 \%)$ & 4.12 (1.12 to 15.2$)$ & $0.03^{*}$ & \\
\hline Marital status & & & & & 0.36 \\
\hline Couple & $51(37 \%)$ & $87(63 \%)$ & 1 & & \\
\hline Single & $7(54 \%)$ & $6(46 \%)$ & 0.43 (0.13 to 0.39$)$ & 0.16 & \\
\hline Widowed/divorced & $22(42 \%)$ & $31(59 \%)$ & 1.04 (0.51 to 2.14 ) & 0.91 & \\
\hline Career & & & & & 0.28 \\
\hline No & $58(41 \%)$ & 84 (59\%) & 1 & & \\
\hline Yes & $22(36 \%)$ & $40(65 \%)$ & 1.46 (0.74 to 2.88$)$ & 0.28 & \\
\hline Salary & & & & & 0.85 \\
\hline No & $21(40 \%)$ & $31(60 \%)$ & 1 & & \\
\hline Yes & $59(39 \%)$ & $93(61 \%)$ & 0.94 (0.46 to 1.89$)$ & 0.85 & \\
\hline Number of underlying diseases (median [IQR]) & $2.0(1.0)$ & $2.0(1.0)$ & 0.74 (0.52 to 1.06$)$ & 0.10 & 0.10 \\
\hline Number of current medications per day (median [IQR]) & $3.0(1.25)$ & $3.0(1.0)$ & $1.06(0.84$ to 1.34$)$ & 0.63 & 0.63 \\
\hline
\end{tabular}

$\mathrm{Cl}$, confidence interval; $\mathrm{IQR}$, interquartile range; $\mathrm{OR}$, odds ratio; $\mathrm{LR}$, likelihood ratio.

tData are presented as $\mathrm{n}(\%)$ unless indicated otherwise.

${ }^{*} P<0.05$

little pharmacological study to support this belief. Thailand's Health Ministry approved the use of a kariyat extract to treat coronavirus disease (COVID)-19 in a pilot program [19].

More than half of the participants with a history of herbal medicine usage did not consider any principles of safe use of herbal medicine before consumption. This finding is in accordance with those of a previous study, which recommended that the knowledge of Thai people in using alternative medicine should be improved [20]. The finding that almost 3 quarters of the health care providers did not place any consideration of herbal medicine usage is unexpected for a university hospital, which provides training for medical students and residents. This may be the result of treatment of elderly patients having multiple issues of concern, such as multiple underlying diseases, drug-drug interactions, drug-disease interaction, pharmacokinetics and pharmacodynamic changes, along with drug side effects, so as the physician may not have had sufficient time to explore complementary and alternative medicine usage in the elderly.

The strengths of the present study are that there are only a few studies on this topic that have been conducted in
Southern Thailand. Moreover, this study explores the awareness of principles of safe use of herbal medicine before consumption, including discussion with health care providers and physician's attention to herbal medicine usage, because few studies in Thailand have made mention of this point. There are some limitations to this study. First, the question about herbal medicine usage within 1 year might cause recall bias, although an effort was made to allow enough time for participants to recall their history of usage. Additionally, deep details of usage, such as dosage, were not included. Second, due to awareness of vision problems in elderly patients, this study used verbal questionnaires, which may have caused some participants to feel distressed when answering, thus, possibly causing an underestimation of prevalence of usage. To counteract this limitation, we explained to participants that their answers would not be reported individually, and it would in no way affect care received from their health care providers. Third, we did not record herbal and conventional medicine interactions. This is an important point to explain to patients when advising them to start, or stop, using herbal medicine. Finally, this 
study was conducted in the PCU of a university hospital, wherein the patients included had a higher amount of underlying diseases when compared with participants in a community setting [5]. A greater number of chronic diseases is recognized as associated with the greater use of herbal medicines [4]. Therefore, health care providers should use caution when applying our results to other settings.

\section{Conclusions}

The finding of a high prevalence of herbal medicine usage by elderly patients coupled with low consultation rates suggests that health care providers should be more aware of herbal medicine usage and should increase their role of initiating the discussion about herbal medicine usage with elderly patients, so as to avoid problems arising from the use of herbal medicine, such as herb-drug interactions or adverse effects. Extending the study setting to other settings, such as the general community, increasing the sample size to increase the statistical power of the study, and evaluating other topics regarding herbal medicine usage such as frequency and dosage and herb-drug interactions are warranted.

Author contributions. TA and SR contributed substantially to the conception and design of the present study. TA, PK, KP, $\mathrm{NN}, \mathrm{ST}$, JJ, JY, and NC curated the data and all authors contributed substantially to its analysis and interpretation. TA, PK, $\mathrm{KP}, \mathrm{NN}, \mathrm{ST}, \mathrm{JJ}, \mathrm{JY}$, and NC contributed substantially to drafting the manuscript, and TA and SR revised it for critical intellectual content. All authors approved the final version submitted for publication and take responsibility for statements made in the published article.

Acknowledgments. We greatly appreciate the assistance of Pitchayanont Ngamchaliew, Narucha Komolsuradej, and Panithan Vajanakomkul for creating the Item Objective Congruence index for our data collection form. We also thank Kittisakdi Choomalee for data analysis and the International Affairs Department for their assistance in editing the English of this paper. The authors did not receive any specific grant for this research from any funding agency in the public, commercial, or not-for-profit sectors.

Conflict of interest statement. The authors have each completed and submitted an International Committee of Medical Journal Editors Uniform Disclosure Form for Potential Conflicts of Interest. None of the authors has any potential or actual conflict of interest to disclose in relation to the present article.
Data sharing statement. Statistical summaries of data sets generated in the present study are included in this published article. The data sets generated and analyzed during the present study are available from the corresponding author for noncommercial purposes on reasonable request after deidentification of data from any person whose data were included in the study.

\section{References}

[1] Zhao C, Wong L, Zhu Q, Yang H. Prevalence and correlates of chronic diseases in an elderly population: a community-based survey in Haikou. PloS One 2018; 13:e0199006. doi:10.1371/journal. pone.0199006

[2] Fatima N, Nayeem N. Toxic effects as a result of herbal medicine intake. In: Larramendy M, Soloneski S, editors. Toxicology: new aspects to this scientific conundrum. Rijeka, Croatia: InTech; 2016, p. 193-208. doi: 10.5772/64468

[3] World Health Organization. Traditional, complementary and integrative medicine [Internet]. Geneva: World Health Organization; 2019 [cited 2019 July 30]. Available from: https://www. who.int/traditional-complementary-integrative-medicine/en

[4] Rashrash M, Schommer JC, Brown LM. Prevalence and predictors of herbal medicine use among adults in the United States. J Patient Exp. 2017; 4: 108-13.

[5] Turkmenoglu FP, Kutsal YG, Dolgun AB, Diker Y, Baydar T. Evaluation of herbal product use and possible herb-drug interactions in Turkish elderly. Complement Ther Clin Pract. 2016; 23:46-51.

[6] Agbabiaka TB, Spencer NH, Khanom S, Goodman C. Prevalence of drug-herb and drug-medicine interactions in older adults: a cross-sectional survey. Br J Gen Pract. 2018; 68:e711-7. doi: 10.3399/ bjgp18X699101

[7] De Smet PAGM. Herbal remedies. N Engl J Med. 2002; 347(25):2046-56.

[8] Arcury TA, Grzywacz JG, Bell RA, Neiberg RH, Lang W, Quandt SA. Herbal remedy use as health self-management among older adults. J Gerontol B Psychol Sci Soc Sci. 2007; 62B:S142-9.

[9] Schnabel K, Binting S, Witt CM, Teut M. Use of complementary and alternative medicine by older adults-a cross-sectional survey. BMC Geriatr. 2014; 14-38. doi: 10.1186/1471-2318-14-38

[10] Sumngern C, Azeredo Z, Subgranon R, Matos E, Kijjoa A. The perception of the benefits of herbal medicine consumption among the Thai elderly. J Nutr Health Aging. 2011; 15:59-63.

[11] Nortier JL, Martinez MC, Schmeiser HH, Arlt VM, Bieler CA, Petein M, et al. Urothelial carcinoma associated with the use of a Chinese herb (Aristolochia fangchi). N Engl J Med. 2000; 342(23):1686-92.

[12] Ko RJ. Adulterants in Asian patent medicines. N Engl J Med. 1998; 339(12):847.

[13] Wongtongdee M, Aimpia A. Use of herbal products in the elderly [Dissertation]. Bangkok: Mahidol Univ.; 2004.

[14] de Souza Silva JE, Santos Souza CA, da Silva TB, Gomes IA, Brito G de C, de Souza Araújo AA, et al. Use of herbal medicines by elderly patients: a systematic review. Arch Gerontol Geriatr. 2014; 59:227-33. 


\section{RASIAN IIII, BIOMEDICINE}

[15] Ayele AA, Tegegn HG, Haile KT, Belachew SA, Mersha AG, Erku DA. Complementary and alternative medicine use among elderly patients living with chronic diseases in a teaching hospital in Ethiopia. Complement Ther Med. 2017; 35:115-9.

[16] Ramathibodi Hospital, Outpatient Department. Complementary and alternative medicine [Internet]. Bangkok: Faculty of Medicine, Ramathibodi Hospital; c2015-15 [cited 2020 Jan 08]. Available from: https://med.mahidol.ac.th/altern_med/th/knowledge/alternativemedicine. [in Thai]

[17] Tan C-H. Usage of herbal medicines in older adults in Singapore. 3rd International Conference on Advanced Clinical Research and Clinical Trials; 2017 September 20-21, Dublin, Ireland. Berkshire, United Kingdom: Conference Series. [cited 2020 Nov 1]. Available

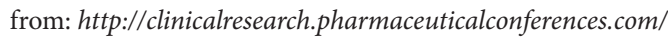
abstract/2017/usage-of-herbal-medicines-in-older-adults-in-singapore

[18] Aekplakorn W. Thai National Health Examination Survey V. 2557 [monograph on the Internet]. Bangkok: NHESO; 2014. [cited 2018 Nov 30]. Available from: http://thaitgri.org/? $p=37869$ [in Thai]

[19] Bangkok Post. COVID-19 fear fuels rush for traditional herbal medication. [Internet] Bangkok: Bangkok Post; 2020 Mar 17 [cited 2021 Jan 08]. Available from: https://www.bangkokpost.com/thailand/ general/1880490/covid-19-fear-fuels-rush-for-traditional-herbalmedication

[20] Unjana R, Leemingsawat W. Knowledge, attitude and behavior of using alternative medicine in Thai people. J Sports Sci Health. 2016; 17: 70-83. [in Thai, English abstract] 